
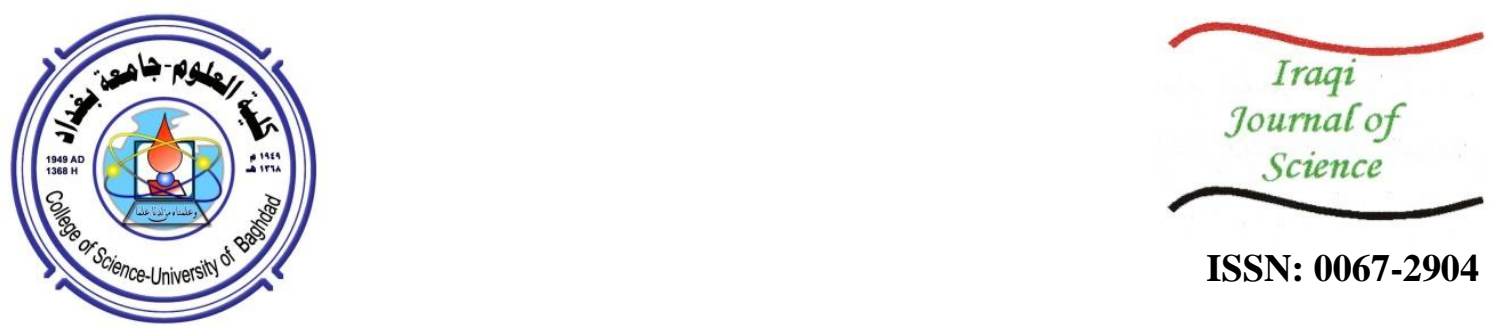

ISSN: 0067-2904

\title{
Gene Expression of pelA and pslA in Pseudomonas Aeruginosa under Gentamicin Stress
}

\author{
Mahmood Abdul Razzaq Hassan AL-Sheikhly ${ }^{1,2}$, Laith N. Musleh ${ }^{2}$, Harith J. F. Al- \\ Mathkhury ${ }^{3}$ \\ ${ }^{1}$ Laboratory Department, Directorate of Technical matters, Ministry of Health, Baghdad, Iraq \\ ${ }^{2}$ Department of Biology, College of Science, University of Anbar, Anbar, Iraq \\ ${ }^{3}$ Department of Biology, College of Science, University of Baghdad, Baghdad, Iraq
}

Received: 7/10/ 2019

Accepted: 19/ 11/2019

\begin{abstract}
Pseudomonas aeruginosa produces an extracellular biofilm matrix that consists of nucleic acids, exopolysaccharides, lipid vesicles, and proteins. Alginate, Psl and Pel are three exopolysaccharides that constitute the main components in biofilm matrix, with many biological functions attributed to them, especially concerning the protection of the bacterial cell from antimicrobial agents and immune responses. A total of 25 gentamicin-resistant $P$. aeruginosa selected isolates were enrolled in this study. Biofilm development was observed in $96 \%$ of the isolates. In addition, the present results clarified the presence of pelA and $p s l A$ in all the studied isolates. The expression of these genes was very low. Even though all biofilms were affected by gentamicin, the results of fold change showed a wide variation. In conclusion, all $P$. aeruginosa isolates carried $\mathrm{psl}$ and $\mathrm{pel}$ regardless of the intensity of the biofilm. A strongly positive correlation with gentamicin minimum inhibitory concentration was noticed.
\end{abstract}

Keywords: PelA, PslA, biofilm, RT-qPCR.

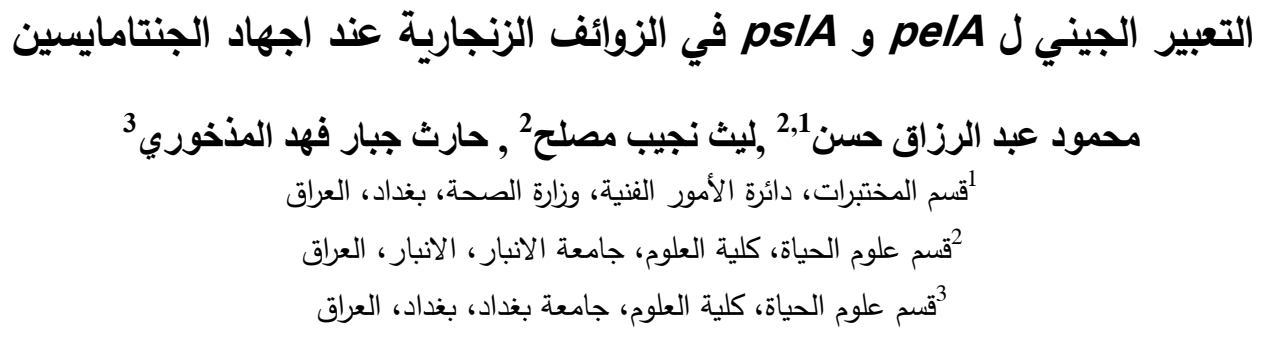




$$
\begin{aligned}
& \text { من ps/A و pelA بغض النظر عن شدة و قوة الغشاء الحياتي. كما لوحظ وجود ارتباط ضعيف بين التركيز }
\end{aligned}
$$

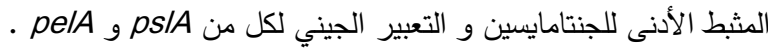

\section{Introduction}

Pseudomonas aeruginosa is a Gram-negative bacterium that is found widely in the environment and engages in various forms of interactions with eukaryotic host organisms. It is an opportunistic pathogen widely spread in humans, giving rise to a broad spectrum of infections in community and healthcare facilities $[1,2]$. Due to the extended spread of $P$. aeruginosa habitats, the control of the organism in a hospital setting is very difficult and it is practically impossible to prevent contamination [3]. The major threat is the infection of immunocompromised persons or those in burns, neonatals, and cancer compartments [4]. Infection of $P$. aeruginosa is still one of the main causes of death among the critically ill and patients with impaired immune systems, in spite of the development of newer and stronger antibiotics [5].

Biofilm production is an important mechanism for the survival of $P$. aeruginosa and its relationship with antimicrobial resistance represents a challenge for patient therapeutics [6]. Biofilms are associated with over $80 \%$ of all microbial infections [7]. Exopolysaccharides and extracellular DNA are important structural components that contribute to the self-assembly of large aggregates or microcolonies that are characteristic of biofilms. P. aeruginosa is capable of producing multiple exopolysaccharides, including alginate, Psl, and Pel [8]. A key component of biofilm formation in $P$. aeruginosa is the biosynthesis of exopolysaccharides known as polysaccharide encoding locus (Pel) and polysaccharide synthesis locus (Psl), which are involved in the formation and maintenance of the structural biofilm scaffold and protection against antimicrobials and host defenses [9]. Although the preference of Pel or Psl is often strain-specific, many isolates are capable of switching between the synthesis of Pel and that of Psl in response to stress to maintain the infection in the host [10]. This adaptive mechanism underscores the importance of developing therapies that target both exopolysaccharides [9].

Aminoglycosides are used to treat many Gram-negative and some Gram-positive infections and, importantly, multidrug-resistant tuberculosis. Among various bacterial species, resistance to aminoglycosides arises through a variety of intrinsic and acquired mechanisms [11]. P. aeruginosa has developed several mechanisms to resist antimicrobial agents that can be associated with high mortality $[12,2]$.

\section{Materials and Methods}

\section{Pseudomonas aeruginosa isolates}

A total of 25 P. aeruginosa isolates were obtained from the Department of Biology, College of Science, University of Anbar. They were originally isolated from different clinical specimens as previously mentioned by AL-Sheikhly et al. [13]. P. aeruginosa ATCC (27853) was used as a quality control strain.

\section{Microplate Biofilm Development Test}

Biofilm formation was determined by microtiter plate assay [14]. Briefly, 24 hours old cultures were kept in tryptic soy broth (TSB) containing $1 \%$ glucose. Thereafter, broth cultures were checked to McFarland standard No. 0.5 using the same medium as diluent. About $200 \mu \mathrm{l}$ of an isolate suspension were transferred into each of three wells of a 96-well flat-bottomed polystyrene plate and incubated for $24 \mathrm{hr}$. at $37^{\circ} \mathrm{C}$. Thereafter, each well was washed twice using sterile deionized water with rough shaking and later dried thoroughly. The adhering bacterial cells were fixed with $200 \mu \mathrm{l}$ of absolute methanol. Afterward, each well was stained with $200 \mu \mathrm{l}$ of $0.1 \%$ crystal violet for 15 minutes. Repetitive washing was performed to remove the excess stain. Later on, the crystal violet bound to the adherent cells was retained with $200 \mu \mathrm{l}$ of ethanol per well. The test was made in triplicates, and the absorbance of wells filled with bacteria-free TSB served as a negative control. The amount of crystal violet removed by ethanol in each well was directly quantified spectrophotometrically by measuring the $\mathrm{OD}_{630}$ using microplate reader. The cut-off value (ODc) was calculated as three standard deviations plus the mean OD of the negative control. Given that, absorbance values represented the intensity of the biofilm formed by the studied isolates on the surface of the microtiter well. The obtained results were categorized into four groups (viz., non-biofilm producer, weak, moderate, and strong). 


\section{The effects of gentamicin at sub-MIC on biofilm formation}

The MIC was assessed for gentamicin by the broth dilution method [15] and was carried out in triplicate. The antibacterial activity was examined after incubation at $37^{\circ} \mathrm{C}$ for $18-24 \mathrm{~h}$. MIC was resolved as the lowest concentration of test samples that resulted in a whole inhibition of the observable growth in the broth.

\section{Detection of pelA and pslA}

\section{A- Extraction of DNA and Polymerase Chain Reaction Amplification}

DNA was extracted from $25 P$. aeruginosa selected isolates using genomic DNA extraction kit (Promega, USA), following the manufacturer's instructions. The purity and concentration of the DNA were estimated by Nanodrop.

\section{B- Primer Selection}

Specific primers that were needed for amplifying a fragment of $16 \mathrm{SrRNA}$, pelA and pslA are listed in Table- 1. Primers were provided in a lyophilized form and dissolved in sterile nuclease-free water to give a final concentration of $100 \mathrm{pmol} / \mu \mathrm{l}$. Afterward, they were stored in a deep freezer until use.

Table 1-Primers utilized in this study

\begin{tabular}{|c|c|c|c|c|}
\hline \multicolumn{2}{|c|}{ Primer name } & Sequence $\left(5^{\prime}-3^{\prime}\right)$ & Product size & Reference \\
\hline \multirow{2}{*}{ pelA } & $\mathrm{F}$ & CCTTCAGCCATCCGTTCTTCT & \multirow{2}{*}{118 bp } & \multirow{2}{*}[10]{} \\
\hline & $\mathrm{R}$ & TCGCGTACGAAGTCGACCTT & & \\
\hline \multirow{2}{*}{ pslA } & $\mathrm{F}$ & ATAAGATCAAGAAACGCGTGGA & \multirow{2}{*}{$70 \mathrm{bp}$} & \multirow{2}{*}[10]{} \\
\hline & $\mathrm{R}$ & TGTAGAGGTCGAACCACACCG & & \\
\hline \multirow{2}{*}{$16 \operatorname{SrRNA}$} & $\mathrm{F}$ & ACCTGGACTGATACTGACACTGA & & \multirow{2}{*}{ [16] } \\
\hline & $\mathrm{R}$ & GTGGACTACCAGGGTATCTAATCCT & & \\
\hline
\end{tabular}

\section{C- Preparation of PCR mixture}

The extracted DNA and primers were added to the PCR premix (Acuu Power PCR pre mix) tubes and vortexed to have homogenous contents. A PCR mixture was made in a total volume of $20 \mu \mathrm{l}$ as described in Table- 2 .

Table 2-Components of the conventional PCR reaction

$$
\text { Component }
$$

Forward primer $(10 \mathrm{pmol})$

Reverse primer (10 pmol)

Nuclease free water

Template DNA

Final volume

Volume $(\mu \mathrm{l})$
$\mathbf{2}$
$\mathbf{2}$
$\mathbf{1 4}$
$\mathbf{2}$
$\mathbf{2 0}$

\section{C- PCR program}

The PCR tubes containing the mixture were transferred to thermo-cycler and the program in Table3 was started [17].

Table 3-Conditions of PCR for pelA and pslA genes

\begin{tabular}{|c|c|c|c|}
\hline Step & Temperature $\left({ }^{\circ} \mathrm{C}\right)$ & Time & No. of cycle \\
\hline Initial Denaturation & 94 & $5 \mathrm{~min}$. & 1 \\
\hline Denaturation & 94 & $30 \mathrm{sec}$. & \multirow{3}{*}{35} \\
\hline Annealing & 52 & $40 \mathrm{sec}$. & \\
\hline Extension & 72 & $50 \mathrm{sec}$. & \\
\hline Final Extension & 72 & $5 \mathrm{~min}$. & 1 \\
\hline
\end{tabular}

\section{Gene expression}

Seven isolates (PA1, PA6, PA50, PA58, PA59, PA60 and PA17) were chosen for this study. In regard to planktonic cells, aliquots of bacterial cells were harvested from media and suspended in 
sterile Muller Hinton Broth. All tubes were incubated overnight at $37^{\circ} \mathrm{C}$. In order to test the effect of gentamicin on gene expression of pelA and pslA, a similar protocol was followed with the use of gentamicin-containing Muller Hinton Broth at sub-MIC.

\section{A- RNA Extraction from $P$. aeruginosa isolates}

RNA was isolated from $P$. aeruginosa planktonic cells using Trizol reagent (Promega, USA) according to the protocol described by the manufacturer.

\section{B- Quantitative reverse transcription-PCR}

In order to assess the gene expression of pelA and pslA, the results were normalized using $16 \operatorname{Sr} R N A$. The reaction mixture is summarized in Table- 4. Moreover, after several trials, the thermo-cycler protocol was optimized and the resultant protocol is listed in Table-5.

Table 4-Components of qRT-PCR used in pelA and pslA genes expression

$\begin{array}{cc}\text { Master mix components } & \text { Volume }(\mu l) \\ \text { qPCR Master Mix } & \mathbf{5} \\ \text { RT mix } & \mathbf{0 . 2 5} \\ \text { Forward primer } & \mathbf{0 . 5} \\ \text { Reverse primer } & \mathbf{0 . 5} \\ \text { Nuclease Free Water } & \mathbf{1 . 7 5} \\ \text { RNA } & \mathbf{2} \\ \text { Total volume } & \mathbf{1 0}\end{array}$

Table 5-qRT-PCR protocol

$\begin{array}{cccc}\text { Step } & \text { Temperature }\left({ }^{\circ} \mathrm{C}\right) & \text { Time } & \text { No. of cycle } \\ \text { Reverse transcription }(\mathrm{RT}) . & \mathbf{3 7} & \mathbf{1 5} \mathbf{~ m i n} & \mathbf{1} \\ \text { Enzyme activation } & \mathbf{9 5} & \mathbf{1 0} \mathbf{~ m i n} . & \mathbf{1} \\ \text { Initial Denaturation } & \mathbf{9 5} & \mathbf{1 5} \mathbf{~ s e c} . & \mathbf{4 0} \\ \text { Denaturation } & \mathbf{5 2} & \mathbf{3 0} \mathbf{~ s e c} . & \\ \text { Annealing } & \mathbf{7 2} & \mathbf{3 0} \mathbf{~ s e c} . & \end{array}$

Expression levels were quantified using relative quantitation. The difference in cycle thresholds $(\Delta \mathrm{Ct})$ and fold changes were evaluated between the treated groups and the calibrators of each gene [18]. Fold change of less than 2-fold was considered insignificant [19]. A melting curve was obtained with temperatures ranging from $60^{\circ} \mathrm{C}$ to $95^{\circ} \mathrm{C}$ with a $1^{\circ} \mathrm{C}$ increase in temperature every one second.

\section{Statistical analysis}

In order to determine the impact of parameters in this study, the statistical package for social science (SPSS) 21.0 and Microsoft excel 2013 were used. Categorical data were formulated as count and percentage. T-test was used in evaluating the effect of gentamicin on biofilm. Regarding other experiments, Fisher exact test and chi-square test were used to describe the association of these parameters. Furthermore, Pearson correlation coefficient was used to check the correlation between fold change and gentamicin sub-MIC. The lowest level of accepted statistical significant difference is bellow or equal to $0.05[20,21]$.

\section{Results and Discussion \\ Biofilm forming capacity}

In the current study, the ability of $P$. aeruginosa biofilm production was evaluated using presterilized 96-well polystyrene microtiter plates, which is considered as a standard test for the detection of biofilm biomass $[14,22]$. According to the results listed in Table- 8, the present study declared that out of 25 gentamicin-resistant isolates, three (12\%) isolates formed a weak biofilm, fourteen (56\%) isolates developed moderate biofilm, whereas seven (28\%) isolates constituted strong biofilm. Nevertheless, only one (4\%) isolate was unable to form a biofilm.

Beenken et al. [23] concluded that the differences in biofilm thickness among isolates might be owing to several reasons; differences of isolates capacity to form biofilm or perhaps differences in primary number of cells that succeeded in adherence, along with differences in the quality and 
quantity of quorum sensing signaling molecules (autoinducers) that are produced from each isolate. A part form moderate biofilm, there is no specific pattern that governs the distribution of biofilm intensity among specimens, i.e. each biofilm intensity is a specimen-specific. Perhaps the reason behind such findings is the variation in the genetic makeup of each strain.

Current results corroborate the findings of other local studies [24, 25, 26]. In addition, there was an agreement with other previous studies $[6,17]$.

This high productivity of biofilm formation may be attributed to the sensitivity of MTP method to measure the few quantities formed. It was considered an important method in studying the early stages of biofilm formation because it uses constant conditions and it can be effective in studying many virulence factors to form biofilms such as pili and flagella. Furthermore, this method was adopted to explore biofilm forming capacity by different types of bacteria [27].

Heydari and Eftekhar [28] indicated that the variation in the ability of isolates to form biofilm is due to the association of the production with its ability to produce B-Lactamase. The isolates produced multiple types of enzymes that produced a strong biofilm compared with isolates that produced one type of enzymes. While, the isolates that do not produce this enzyme are unable to form biofilm.

\section{The Effects of Gentamicin on Biofilm Formation}

The results of the present study, summarized in Table- 6, revealed that gentamicin has significantly (P $<0.05$ ) decreased the density of biofilm formation in four isolates (PA1, PA58, PA59, and PA60). While, no change in biofilm intensity was detected in two isolates (PA6 and PA50). Furthermore, gentamicin induced biofilm formation significantly $(\mathrm{P}<0.05)$ in only one isolate PA17. Yet, the effect differs insignificantly from one isolate to another.

Table 6-The formation of biofilm by $P$. aeruginosa treated with gentamicin at sub-MIC.

\begin{tabular}{|c|c|c|c|c|c|c|c|c|}
\hline \multirow{2}{*}{$\begin{array}{l}\text { Code } \\
\text { of } \\
\text { Isolates }\end{array}$} & \multicolumn{3}{|c|}{ Before Treatment } & \multicolumn{4}{|c|}{ After Treatment } & \multirow[t]{2}{*}{ P-Value } \\
\hline & $\mathrm{OD}_{630}$ & SD & $\begin{array}{l}\text { Biofilm } \\
\text { intensity }\end{array}$ & $\begin{array}{c}\text { Sub- } \\
\operatorname{MIC}(\mu \mathrm{g} / \mathrm{ml})\end{array}$ & $\mathrm{OD}_{630}$ & SD & $\begin{array}{c}\text { Biofilm } \\
\text { intensity }\end{array}$ & \\
\hline PA1 & 0.420 & 0.099 & Moderate & 8 & 0.0663 & 0.0092 & Weak & 0.024 \\
\hline PA6 & 0.302 & 0.136 & Weak & 256 & 0.0606 & 0.0025 & Weak & 0.091 \\
\hline PA50 & 0.322 & 0.011 & Weak & 16 & 0.0753 & 0.0045 & weak & 0.0001 \\
\hline PA58 & 0.769 & 0.126 & Strong & 16 & 0.0743 & 0.0046 & Weak & 0.010 \\
\hline PA59 & 1.015 & 0.103 & Strong & 8 & 0.0916 & 0.0065 & Weak & 0.004 \\
\hline PA60 & 0.493 & 0.136 & Moderate & 16 & 0.0813 & 0.0025 & Weak & 0.034 \\
\hline PA17 & 0.154 & 0.022 & $\begin{array}{c}\text { Non biofilm } \\
\text { producer }\end{array}$ & 512 & 0.0583 & 0.0035 & Weak & 0.016 \\
\hline
\end{tabular}

A similar variation was noticed by other studies $[29,30]$. Such variation may be considered normal due to the types of studied isolates and their source as well as the genetic makeup of isolates, or the laboratory conditions that accompanied the detection of the sub-MIC.

It has been reported that when antibiotics are present at concentrations below the MIC, it can significantly induce biofilm formation in a variety of bacterial species in vitro. Kaplan [31] reported that the first study that demonstrated that the sub-MIC of antibiotics can induce bacterial biofilm formation in vitro was reported in 1988 by Gordon Christensen.

Marr et al. [32] also investigated the mechanism of aminoglycoside-induced biofilm formation in P. aeruginosa, whereas Hoffman et al. [33] found that the sub-MIC concentrations of tobramycin 
readily induced $P$. aeruginosa biofilm formation. Otani et al. [34] noticed that the ceftazidime at subMIC significantly inhibited $P$. aeruginosa biofilm formation.

Generally, the antibiotics reduced the biofilm formation; however, several studies showed that the antibiotics could significantly induce biofilm formation depending on antibiotics class and the bacterial strain [30].

\section{Molecular Identification}

\section{A- Genomic DNA Extraction and Purity}

The bacterial genomic DNA was extracted from overnight cultures of isolates. It was found that the purity ranged from 1.88 to $2.01 \mathrm{ng} / \mu \mathrm{l}$, while the concentration fluctuated between 59 and $539 \mathrm{ng} / \mu \mathrm{l}$. Furthermore, Figure- 1 illustrates the presence of a single band of extracted DNA, which indicates the efficiency of the method used in the extraction of DNA.

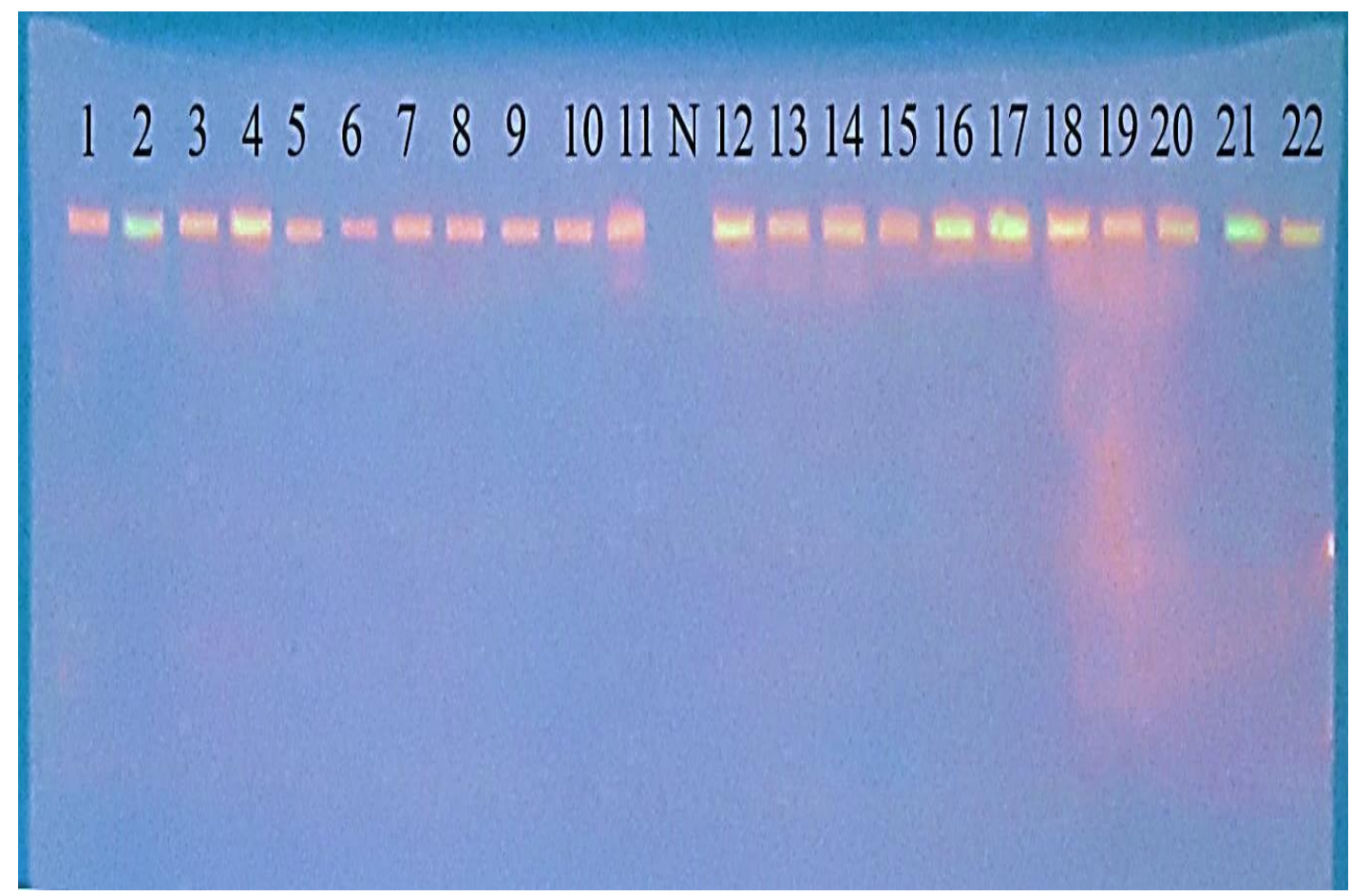

Figure 1-Agarose gel electrophoresis of DNA bands from $P$. aeruginosa isolates in (1\% agarose, 5 $\mathrm{V} / \mathrm{cm}$ ) stained with Ethidium Bromide. Lane N represents negative control.

\section{Detection of pelA and pslA}

PCR was conducted over 25 isolates, using the pelA and pslA specific primers to amplify the constitutional genes pelA and pslA. The present results clarified the presence of these genes in all $P$. aeruginosa isolates Figures-(2 and 3).

The results of the current study are in agreement with those of Maita and Boonbumrung [17] who stated that the percentage of pelA was $97.8 \%$ while that of pslA was $94.9 \%$, which were found in almost all clinical isolates of $P$. aeruginosa. Al-Wrafy et al. [35] suggested that biofilm represents an important virulence factor for these bacteria and plays a role in $P$. aeruginosa infections and avoidance of immune defense mechanisms; it can protect the bacteria from antibiotics. Alginate, Psl and Pel are three exopolysaccharides which constitute the main components in biofilm matrix, with many biological functions attributed to them, especially with respect to the protection of the bacterial cell from antibiotics and the immune responses. 


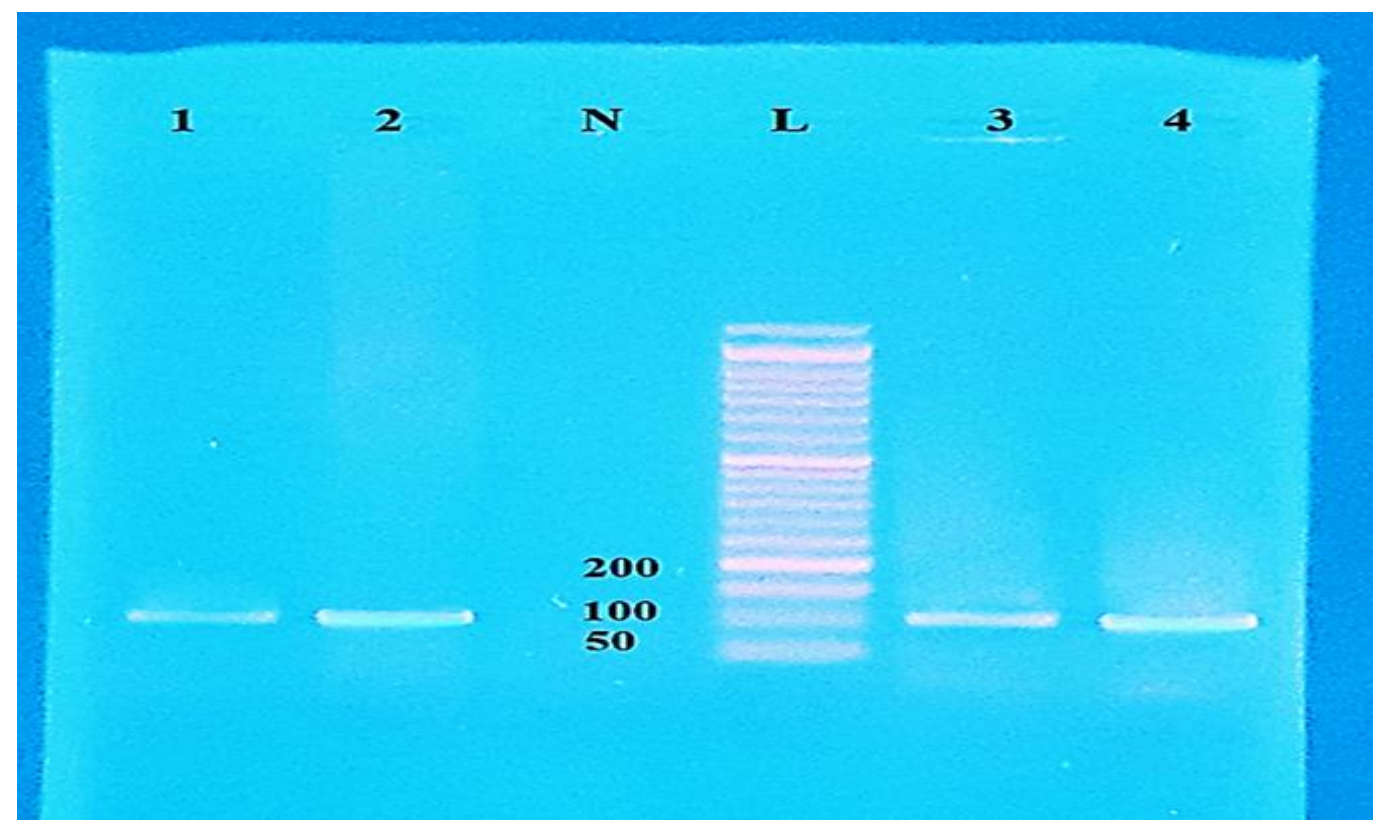

Figure 2-Agarose gel electrophoresis (1.5\% agarose, $5 \mathrm{~V} / \mathrm{cm})$ of pelA (118bp). Lane L represents 50 bp DNA ladder, Lanes 1-4 represent bands of pelA (118bp).

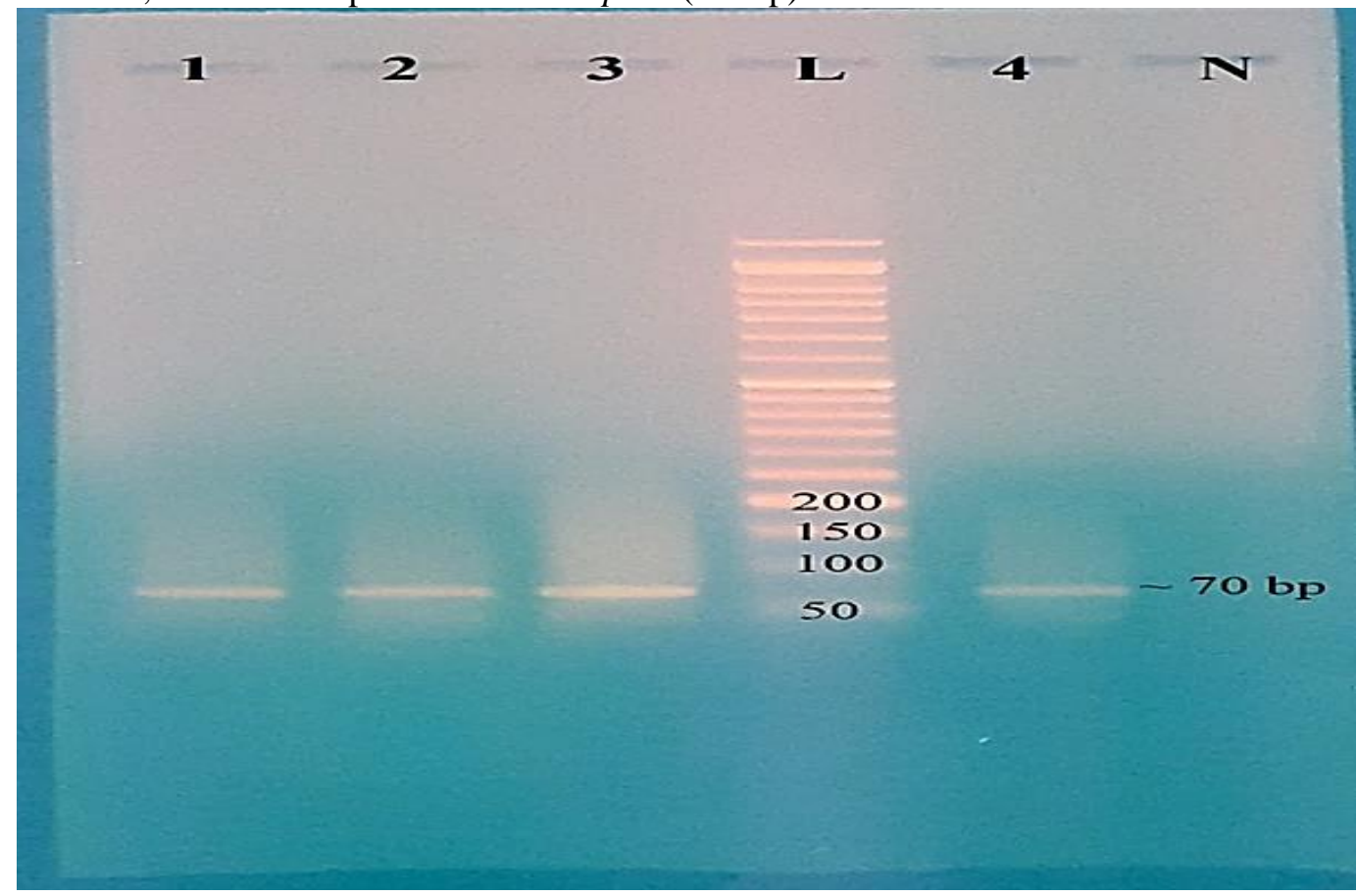

Figure 3-Agarose gel electrophoresis (1.5\%agarose, $5 \mathrm{~V} / \mathrm{cm}$ ) of $p s l A$ (70bp). Lane L represents $50 \mathrm{bp}$ DNA ladder, Lane $\mathrm{N}$ denotes negative control. Lanes 1, 2, 3, and 4 represent bands of pslA (70bp).

Many local studies investigated other types of biofilm genes. Musafer [24] revealed that the OprD plays a major role in the acquired resistance to imipenem, while it also participates in biofilm formation; AL-Dulami [26] observed that lasI has an important role in the production of biofilm. ALSabawi [25] found that the pelF is responsible for biofilm formation.

Recalling the results of biofilm formation, one isolate was unable to form biofilm despite carrying both of pelA and pslA. Obviously, it can be realized that there are other genes responsible for biofilm formation. Accordingly, the presence of these genes could not predict which isolate will produce biofilm.

Although the preference of Pel or Psl is often strain-specific, many isolates are capable of switching between the synthesis of Pel and that of Psl in response to stress to maintain infection in the host [10]. This adaptive mechanism underscores the importance of developing therapies that target both exopolysaccharides [9]. 


\section{Gene expression}

The expression of pelA and pslA of $P$. aeruginosa biofilm was studied by RT-qPCR. The isolates were characterized by different sub-MIC levels of gentamicin $(8,16,256$, and $512 \mu \mathrm{g} / \mathrm{ml})$. Seven isolates (PA1, PA6, PA17, PA50, PA58, PA59, and PA60) enrolled in this experiment were chosen for the following reasons:

a)Different biofilm intensity.

b)Six of them are of the same clinical source (PA1, PA6, PA50, PA58, PA59, and PA60).

c)Isolate PA17 was a biofilm non-producer.

RNA Extraction from $P$. aeruginosa isolates and RT-qPCR

The isolates PA1 and PA60 are moderate biofilm formers, PA58 and PA59 are strong biofilm producers, and PA6 and PA50 are weak biofilm producers. While, isolate PA17 is non-biofilm former. RNA was extracted from the aforementioned isolates. Total RNA was extracted by using TRIzol ${ }^{\mathrm{TM}}$ Reagent and its concentration was measured by using quantusflorometer. It ranged from 59.9 to 245 $\mathrm{ng} / \mu \mathrm{l}$.

\section{Gene expression of pelA and pslA}

Obviously, gene expression levels presented in Table-7 were very low in all isolates; however, such results were explained by Huse et al. [36]; he revealed that biofilm polysaccharides production is increased throughout the infection. Furthermore, an increase in gene expression of one gene corresponded with a decrease in the other gene. Colvin et al. [10] stated that such overlapping is owing to compensating the lack of gene expression of one gene with overexpression in the other one.

Albeit all biofilms were affected by gentamicin at sub-MIC (Table-6), the results of fold change presented a wide variation. For instance, both genes have suffered an increase in the isolate PA6. Nevertheless, the isolate PA50 showed an increase in fold change of pelA, whereas the isolates PA60 and PA17 showed an increase in fold change of pslA. A part of these three isolates (PA1, PA58 and PA59), none of the rest developed an increase; on the contrary, both genes were under-expressed. Such findings, perhaps, emphasize the contribution of other genes alongside with pel and psl. Remarkably, it was noted that the isolate PA17 was unable to form biofilm before the treatment with gentamicin; hitherto, it formed the biofilm when treated with gentamicin at $512 \mu \mathrm{g} / \mathrm{ml}$ (sub-MIC). The expression of both genes (pelA and pslA) before treatment with gentamicin was low, but the gene expression of the $p s l A$ increased after treatment. This indicates that this gene plays a role in the formation of biofilm in this particular isolate (PA17) at least. Yet, it might play a role in the formation of biofilm in the rest of the selected isolates (PA6and PA60). Moreover, a strong correlation was found $(\mathrm{r}=0.999)$ between the fold change of pelA and pslA.

Table 7-Results of gene expression and fold change for pelA in P. aeruginosa biofilm

\begin{tabular}{|c|c|c|c|c|c|c|}
\hline \multirow{2}{*}{$\begin{array}{l}\text { Isolate } \\
\text { Code }\end{array}$} & \multirow{2}{*}{$\begin{array}{l}\text { Source } \\
\text { of } \\
\text { isolated }\end{array}$} & \multirow{2}{*}{$\begin{array}{c}\text { Gentamicin } \\
\text { at sub-MIC } \\
(\mu \mathrm{g} / \mathrm{ml})\end{array}$} & \multicolumn{2}{|c|}{ pelA } & \multicolumn{2}{|c|}{ pslA } \\
\hline & & & $\begin{array}{c}\text { Gene } \\
\text { expression }\end{array}$ & Fold change & $\begin{array}{c}\text { Gene } \\
\text { expression }\end{array}$ & $\begin{array}{c}\text { Fold } \\
\text { change }\end{array}$ \\
\hline PA1 & Burn & 8 & $2.15792 \times 10^{-5}$ & 0.56 & 0.0019667 & 0.76 \\
\hline PA6 & Burn & 256 & $8.39564 \times 10^{-5}$ & 106.44 & 0.0332615 & 1218.61 \\
\hline PA50 & Burn & 16 & $3.58399 \times 10^{-6}$ & 1.01 & $\underset{6}{8.17698 \times 10^{-}}$ & 0.47 \\
\hline PA58 & Burn & 16 & $1.69533 \times 10^{-6}$ & 0.28 & 0.0003599 & 0.91 \\
\hline PA59 & Burn & 8 & $4.14556 \times 10^{-6}$ & 0.04 & 0.0001876 & 0.06 \\
\hline PA60 & Burn & 16 & $4.82848 \times 10^{-6}$ & 0.58 & 0.0002125 & 52.95 \\
\hline PA17 & Wound & 512 & $2.03284 \times 10^{-7}$ & 0.19 & $\underset{5}{2.98895 \times 10^{-}}$ & 1.71 \\
\hline
\end{tabular}


The results of the current study were somewhat in agreement with a previous study of Maita and Boonbumrung [17] who revealed that the biofilm formation is accompanied by drastic changes in gene regulation. The formation of microcolonies in $P$. aeruginosa has been attributed to many factors. These include type IV pili, flagella, free DNA, alginate and Pel and Psl polysaccharides. Even if one of the factors is not functioning, the biofilm is still able to perform well.

The findings of the present study clarified a weak correlation $(r=0.306)$ between antibiotic concentration at sub-MIC and folding change for pelA. In addition, a weak correlation was observed ( $\mathrm{r}$ $=0.302$ ) between antibiotic concentration at sub-MIC and folding change for pslA (Table- 8). On the contrary, the results of the present study disagreed with Coulon et al [37] who linked the Pel production with aminoglycoside tolerance in biofilms formation.

Table 8-Correlation between fold change (pelA, pslA) and antibiotic concentration at sub-MIC

\begin{tabular}{|c|c|c|}
\hline Groups & Mean \pm SE & Correlation coefficient \\
\hline Gentamicin (Sub-MIC) & $118.857 \pm 73.951$ & \multirow{2}{*}{$\begin{array}{c}0.306 \\
\text { (Weak) }\end{array}$} \\
\hline Folding Change (pelA) & $15.586 \pm 15.143$ & \\
\hline Gentamicin (Sub-MIC) & $118.857 \pm 73.951$ & \multirow{2}{*}{$\begin{array}{c}\mathbf{0 . 3 0 2} \\
\text { (Weak) }\end{array}$} \\
\hline Folding Change ( $p s l A)$ & $182.210 \pm 172.890$ & \\
\hline
\end{tabular}

\section{$\mathrm{SE}=$ Standard Error}

Colvin et al. [10] and Thellin et al. [38] suggested that there was significant strain-to-strain variability in the contribution of Pel and Psl to mature biofilm structure. A similar interpretation suggested that Pel and Psl can serve a redundant function as a structural scaffold in mature biofilms. Depending on the strain studied, the role of Pel and Psl in biofilm formation can vary drastically.

Maita and Boonbumrung [17] stated that the antibiotic resistance of bacteria due to biofilm formation contributes to the persistence of bacterial cells and causes problems in the complete eradication of infection. The structure of biofilms is increasingly recognized as a crucial factor in the persistence of several infections. Chronic infections have been remarkably demonstrated to involve biofilm production, especially those infections associated with indwelling devices such as catheters and prostheses. The ability of the biofilm to contribute to bacterial protection is widely different among microbes. Biofilms not only contribute to the resistance mechanisms against a broad-spectrum of antibiotics but also against host immune systems. The antibiotic susceptibility of biofilm-producing bacteria was reduced because of a restricted antibiotic penetration, adaptive response and the presence of persisting cells.

In conclusion, all $P$. aeruginosa isolates carried psl and pel despite the intensity of biofilm. However, a weak correlation was noticed between the gene expression and gentamicin MIC.

\section{References}

1. Granato, T.E., Ziegenhain, C., Marvig, L. R. and Kümmerli, R. 2018. Virulence evolution in the opportunistic bacterial pathogen Pseudomonas aeruginosa. doi: http://dx.doi.org/10.1101/250845.

2. Panga, Z., Raudonisb, R., Glickc, B.R., Lina, T-J.and Cheng, Z.2019. Antibiotic resistance in Pseudomonas aeruginosa: mechanisms and alternative therapeutic. Biotechnol. Advances, 37: 177192.

3. Davies J. 1994. Inactivation of antibiotics and the dissemination of resistance genes. Science. 264(5157): 375-382.

4. Khalil, M.A., Ibrahimm, S. F. and Mohamed, A.F. 2015.Comparative study of virulence factors among ES $\beta$ L-producing and nonproducing Pseudomonas aeruginosa clinical isolates. Turk. $J$. Med. Sci. 45(1): 60-69. 
5. Amoon, R.H., Abdallha, A.H., Sharif, A.O., Moglad, E.H., Altyb, H.N., Elzaki, S.G. and Salih, M.A. 2018. Molecular characterization of Pseudomonas aeruginosa isolates from Sudanese patients: A cross-sectional study [version 1; referees: awaiting peer review] F1000Research, 7: 1135

6. Costa - Limaa, J.L., Alves, L.R, Araújo Jacomé, P.R.L, Netoc, J.P.B., Maciel, M.A.V. and Morais, M.M.C. 2018. Biofilm production by clinical isolates of Pseudomonas aeruginosa and structural changes in LasR protein of isolates non biofilm-producing. Braz.J. Infect. Dis, 22(2): 129-136.

7. Koziróg, A., Otlewska, A. and Brycki, B. 2018. Viability, Enzymatic and Protein Profiles of Pseudomonas aeruginosa Biofilm and Planktonic Cells after Monomeric/Gemini Surfactant Treatment. Molecules, 23 (1294).

8. Jennings, L.K., Storek, K.M., Ledvina, H.E., Coulon, C., Marmont, L.S., Sadovskaya, I., Secor, P.R., Tseng, B.S., Scian, M., Filloux, A., Wozniak, D.J., Howell, P.L. and Parsek, M.R. 2015. Pel is a cationic exopolysaccharide that cross-links extracellular DNA in the Pseudomonas aeruginosa biofilm matrix. Proc. Natl. Acad. Sci. USA, 112(36): 11353-11358

9. Baker, P., Hill, J.P., Snarr, D.B., Alnabelseya, N., Pestrak, J.M., Lee, J.M., Jennings, K.L., Tam, J., Melnyk, A.R., Matthew, R., Parsek, R.P., Sheppard, C.D., Wozniak, J.D. and Howell, L.P. 2016. Exopolysaccharide biosynthetic glycoside hydrolases can be utilized to disrupt and prevent Pseudomonas aeruginosa biofilms. Sci. Adv, 2: 1150-1632.

10. Colvin, K.M., Irie, Y., Tart, C.S., Urbano, R., Whitney, J.C., Ryder, C., Howell, P.L., Wozniak, D.J. and Parsek, M.R. 2012. The Pel and Psl polysaccharides provide Pseudomonas aeruginosa structural redundancy within the biofilm matrix. Environ. Microbiol, 14: 1913-1928.

11. Garneau-Tsodikova, S. and Labby, K.J. 2016. Mechanisms of Resistance to Aminoglycoside Antibiotics: Overview and Perspectives. Med.Chem, 7(1): 11-27. doi:10.1039/C5MD00344J.

12. Azam, M.W. and Khan, A.U. 2019. Updates on the pathogenicity status of Pseudomonas aeruginosa. Drug Discovery Today, 24(1): 350-359.

13. AL-Sheikhly, M.A., Musleh, L.N. and Al-Mathkhury, H.J.F .2019. Distribution of pslA among Local Isolates of Biofilm-Producing Pseudomonas aeruginosa. I.J. Pharma. R. (In Press).

14. Atshan, S.S., Nor-Shamsudin, M., Sekawi, Z., Lung, L.T., Hamat, R.A., Karunanidhi, A., Ali, A., Ghaznavi-Rad, E., Ghasemzadeh-Moghaddam, H., Chong Seng, J.S., Nathan, J.J. and Pei, C.P. 2012. Prevalence of adhesion and regulation of biofilm-related genes in different clones of Staphylococcus aureus. J. Biomed. Biotechnol, 972-976. doi: 10.1155/2012/972-976.

15. Andrews, J.M. 2001. Determination of minimum inhibitory concentrations. J. Antimicrob. Chemotherapy, 48: 5-16.

16. Goldsworthy, M. J. H. 2008. Gene expression of Pseudomonas aeruginosa and MRSA within a catheter-associated urinary tract infection biofilm model. Bioscience Horizons, 1(1):28-37

17. Maita, P. and Boonbumrung, K. 2014. Association between biofilm formation of $P$. aeruginosa clinical isolates versus antibiotic resistance and genes involved with biofilm. J. Chem and Pharm.R, 6(5): 1022-1028.

18. Livak, K.J. and Schmittgen, T.D. 2001. Analysis of relative gene expression data using real-time quantitative PCR and the -2(Delta CT) Method. Methods, 25(4): 402-408.

19. Rasigade, J. P., Moulay A., Lhoste Y., Tristan A., Bes M.and Vandenesch, F. 2011. Impact of subinhibitory antibiotics on fibronectin-mediated host cell adhesion and invasion by Staphylococcus aureus. BMC. Microbiol, 11: 26310.

20. Rosner, B. 2010. Fundamentals of Biostatistics; Brooks/cole/cengage learning.Inc., Boston, USA.

21. Negi, K.S. 2012. Methods in biostatistics: AITBS publishers, INDIA, Delhe1st ed.

22. Azeredo,J.,Azevedo,N.F.,Briandet,R.,Cerca,N.,Coenye,T.,Costa,A.R.,Desvaux,M.,Di

Bonaventura,G., Hébraud,M., Jaglic,Z., Kačániová, M., Knøchel, S., Lourenço ,A., Mergulhão, F., Meyer, R.L., Nychas, G., Simões ,M., Tresse, O. and Sternberg, C. 2017. Critical review on biofilm methods. Critical Reviews in Microbiology, 43(3): 313-351.

23. Beenken, K. E., Mrak, L. N., Griffin, L. M., Zielinska, A.K., Shaw, L.N., Rice, K.C., Horswill, A.R., Bayles, K.W. and Smeltzer, M.S. 2010. Epistatic relationships between sarA and agr in Staphylococcus aureus biofilm formation. PLoS One, 24:5(5): 10790.

24. Musafer, H.K. 2013. Role of oprD Gene in Biofilm Formation and Imipenem Resistance in Pseudomonas aeruginosa. Ph.D. Thesis. College of Science. University of Baghdad. Iraq. 
25. Al-Sabawi, B.A.M. 2017. Gene Expression Variation of Some Virulence Factors of Pseudomonas aeruginosa Isolated from Some Pathogenic and Environmental Cases. M.Sc. Thesis. Department of Biology. College of Science. University of AL-Anbar, Iraq.

26. Al-Dulami, H.F.L. 2017. Assessment The Effect of Quorum Sensing genes (lasI, rhlI) and Some Plant Extracts on Some Virulence Factors of Pseudomonas aeruginosa Isolated from Different Clinical Sources. M.Sc. Thesis. Department of Biology. College of Science. University of Anbar, Iraq.

27. Saxena, S., Banerjee, G., Garg, R. and Singh, M. 2014. Comparative Study of Biofilm Formation in Pseudomonas aeruginosa Isolates from Patients of Lower Respiratory Tract infection. J. Clin. and Dia.Res, 8(5): 9-11.

28. Heydari, S. and Eftekhar, F. 2014. Biofilm Formation and $\beta$-Lactamase Production in Burn Isolates of Pseudomonas aeruginosa. Jundishapur. J Microbiol, 8(3): e15514.

29. Aka, S.T. and Haji, S.H.2015. Sub-MIC of antibiotics induced biofilm formation of Pseudomonas aeruginosa in the presence of chlorhexidine. Brazil. J. Microbiol, 46(1): 149-154.

30. Zhou, L., Li, T., An,J., Liao,C., Li,N. and Wang,X. 2017. Sub-minimal inhibitory concentration (sub-MIC) of antibiotic induces electroactive biofilm formation in bio electrochemical systems. Water. Research, 125(15): 280-287.

31. Kaplan, J.B. 2011. Antibiotic-induced biofilm formation. Int. J. Artif. Organs, 34(9): 737-751. DOI: $10.5301 /$ ijao.5000027

32. Marr, A.K., Overhage, J., Bains, M. and Hancock, R.E. 2007. The Lon protease of Pseudomonas aeruginosa is induced by aminoglycosides and is involved in biofilm formation and motility. Microbiol, 153 (2):474-482.

33. Hoffman, L.R., Argenio, D.A. and MacCoss, M.J. 2005. Aminoglycoside antibiotics induce bacterial biofilm formation. Nature, 436(7054): 1171-1175. Medline doi:10.1038/nature03912

34. Otani, S., Hiramatsu, K., Hashinaga, K., Komiya, K., Umeki, K., Kenji Kishi,K. and Kadota ,J-I. 2018. Sub-minimum inhibitory concentrations of ceftazidime inhibit Pseudomonas aeruginosa biofilm formation. J. of Infect. \& Chemotherapy, 24(6): 428-433.

35. AL-Wrafy, F., Brzozowska, E., Górska, S. and Gamian, A. 2017. Pathogenic factors of Pseudomonas aeruginosa -the role of biofilm in pathogenicity and as a target for phage therapy. Postepy. Hig. Med. Dosw. (online), 70: 78-91.

36. Huse, H.K., Kwon, T., Zlosnik, J.E., Speert, D.P., Marcotte, E.M. and Whiteley, M.2013. Pseudomonas aeruginosa enhances production of a non-alginate exopolysaccharide during longterm colonization of the cystic fibrosis lung. PloS. One, 8(12): 82621.

37. Coulon, C., Vinogradov, E., Filloux, A.and Sadovskaya, I.2010. Chemical analysis of cellular and extracellular carbohydrates of a biofilm-forming strain Pseudomonas aeruginosa PA14. PLoS One, 5: e14220. [PubMed: 21151973]

38. Thellin, O., Zorzi, W., Jolois, O., Elmoualij, B., Duysens, G. and Cahay, B. 2015. In vitro approach to study the synergistic effects of tobramycin and clarithromycin against Pseudomonas aeruginosa biofilms using prokaryotic or eukaryotic culture media. Int. J. Antimicrob. Agents, 46: 33-38. 